\title{
CONSIDERATIONS FOR AN INTEGRATED UAS CNS ARCHITECTURE ${ }^{\mathbf{1}}$
}

\author{
Fred L. Templin, The Boeing Company, Seattle, WA \\ Raj Jain, Washington University in Saint Louis, St Louis, MO \\ Greg Sheffield, The Boeing Company, St Louis, MO \\ Pedro Taboso-Ballesteros, The Boeing Company, Madrid, Spain \\ Denise Ponchak, NASA Glenn Research Center, Cleveland, $\mathrm{OH}$
}

\section{Abstract}

The National Aeronautics and Space Administration (NASA) Glenn Research Center (GRC) is investigating revolutionary and advanced universal, reliable, always available, cyber secure and affordable Communication, Navigation, Surveillance (CNS) options for all altitudes of UAS operations. In Spring 2015, NASA issued a Call for Proposals under NASA Research Announcements (NRA) NNH15ZEA001N, Amendment 7 Subtopic 2.4. Boeing was selected to conduct a study with the objective to determine the most promising candidate technologies for Unmanned Air Systems (UAS) airto-air and air-to-ground data exchange and analyze their suitability in a post-NextGen NAS environment. The overall objectives are to develop UAS CNS requirements and then develop architectures that satisfy the requirements for UAS in both controlled and uncontrolled air space. This contract is funded under NASA's Aeronautics Research Mission Directorates (ARMD) Aviation Operations and Safety Program (AOSP) Safe Autonomous Systems Operations (SASO) project and proposes technologies for the Unmanned Air Systems Traffic Management (UTM) service.

There is a need for accommodating large-scale populations of Unmanned Air Systems (UAS) in the national air space. Scale obviously impacts capacity planning for Communication, Navitation, and Surveillance (CNS) technologies. For example, can wireless communications data links provide the necessary capacity for accommodating millions of small UASs (sUAS) nationwide? Does the communications network provide sufficient Internet Protocol (IP) address space to allow air traffic control to securely address both UAS teams as a whole as well as individual UAS within each team? Can navigation and surveillance approaches assure safe route planning and safe separation of vehicles even in crowded skies?

Our objective is to identify revolutionary and advanced CNS alternatives supporting UASs operating at all altitudes and in all airspace while accurately navigating in the absence of navigational aids. These CNS alternatives must be reliable, redundant, always available, cyber-secure, and affordable for all types of vehicles including small UAS to large transport category aircraft. The approach will identify CNS technology candidates that can meet the needs of the range of UAS missions to specific air traffic management applications where they will be most beneficial and cost effective.

\section{Introduction}

This paper discusses considerations for Unmanned Aircraft (UA) classification, UAS Mission Classification, and demand forecasts. It further observes the NASA Unmanned Aircraft System Traffic Management (UTM) concept of operations [1]. It is clear that similar work is being carried out in several other forums such as FAA, RTCA, EUROCAE, ICAO, and ITU. Our goal is to study what has already been done by these standards and regulatory organizations, provide an independent assessment, and fill in the gaps where necessary. In particular, our emphasis is on features of the UAS and missions that affect the requirements and architecture.

We study the UAS classifications by DoD, ASTM, EUROCAE, and RTCA and propose a version that is a modification of these but allows both designers and regulators to easily identify an UAS class.

EUROCAE, ITU, and RTCA have also classified UAS missions. The paper reviews these

\footnotetext{
${ }^{1}$ This study is sponsored in part by NASA Contract NNA16BD84C.
} 
classifications and presents a new classification that includes the level of autonomy since that affects the communication traffic significantly.

UAS volume forecast is the next important consideration that affects the CNS requirements. We study the forecast from ITU, RTCA, and FAA and adopt the latest forecast that seems most realistic. These considerations have helped us set a number of requirements for CNS which are reported in a companion paper [2].

We further note that, although each UAS consists of both the Unmanned Aircrafts (UAs) themselves and any supporting infrastructure (e.g., satellites, cell towers, etc.), the term "UAS" is used in the literature to refer to both the system in its entirety as well as an individual aircraft. This document notes the ambiguity and recommends a dialogue on adopting a common terminology that differentiates the individual unmanned aircraft from the UAS system as a whole.

The rest of this paper is organized as follows. Section 2 discusses UAS classification. We build on the classifications used by Department of Defense, ASTM, EUROCAE, and RTCA. Section 3 discusses UAS missions. ITU and EUROCAE have both handled this issue. We build upon these to propose one that helps in setting the requirments. Section 4 provides a brief discussion CNS needs while Section 5 summarizes the demand forecasts from various sources.

\section{UAS Classification}

Over the past 20 years, several other organizations have already proposed classifications of UASs. We begin with a brief overview of these previous classifications. In this section, we present UAS classifications by Department of Defense (DoD), ASTM, EUROCAE, and RTCA.

\subsection{DoD UAS Classification}

The United States Department of Defense was one of the first organizations to use the terms "Drones" or UASs. They classify UASs in 5 groups as shown in [3]:

- Group 1: This group consists of UASs that are less than $20 \mathrm{lb}$ in weight, stay below
$1200 \mathrm{ft}$ above ground level (AGL), and travel at speeds less than 100 knots or 100 nautical miles per hour. A nautical mile [4] is the distance between two parallels of latitude separated by $1 / 60^{\text {th }}$ degree (1 minute angle). A knot is equal to 1.852 $\mathrm{km} /$ hour or 1.151 miles per hour. Examples of Group 1 drones are US Air Force (USAF)/US Navy (USN) T-Hawk, US Marine Corps (USMC)/US Special Ops Command (USSOCOM) Wasp, US Army (USA)/USSOCOM/USMC Puma, USA/USN/USSOCOM RQ-11 Raven, and USA Nano. This group is also called micro/mini UAs. However, the contemporary terms Micro UAS and Mini UAS are not synonymous with this class.

- Group 2: This group consists of UASs that are 21 to $55 \mathrm{lb}(25 \mathrm{~kg})$ in weight and fly below 3500 AGL at speeds less than 250 knots. An example is the USN ScanEagle. This class is also called "Small Tactical". The contemporary term "Small UAS (sUAS)" is not synonymous with this class. It is actually a superset of this group.

- Group 3: This group consists of UASs that are 56 to $1320 \mathrm{lb}(600 \mathrm{~kg})$ in weight, fly below "Flight Level 180." Flight level [4] measures the vertical altitude using a barometer in terms of air pressure relative to the sea-level pressure. This helps keep aircrafts at a safe vertical distance in spite of local variations in ground or sea levels. It is not necessarily the same as above mean sea level (MSL) or above ground level (AGL). In the United States, FL180 is the lowest altitude at which the aircrafts start using pressure to measure altitude. Below this they use AGL. The corresponding AGL is $18000 \mathrm{ft}$. In Europe, aircrafts use FL at as low as $3000 \mathrm{ft}$ AGL. Examples of Group 3 UASs are USN/USMC STUAS, USA/USMC/SOCOM RQ-7 Shadow, and USSOCOM EUAS. This group is also called "Tactical."

- Group 4: This group consists of UASs weighing more than $1320 \mathrm{lb}$ and flying below FL180. Examples of such UASs are 
USAF MQ-1B Predator, USA RQ-5 Hunter, USA MQ-1C Gray Eagle, and USN MQ-88/C Fire Scout. This group is also called "Persistent."

- Group 5: This group consists of UAS weighing more than $1320 \mathrm{lb}$ and flying above FL180. Examples are USAF MQ-9 Reaper, USAF RQ-4B Global Hawk, USN MQ-4C Triton, and USN Uclass. This group is also called "Penetrating."

Key impacts of DoD's classification are the weight and height bounds. The DoD UAS Classification hierarchy is shown in Figure 1:

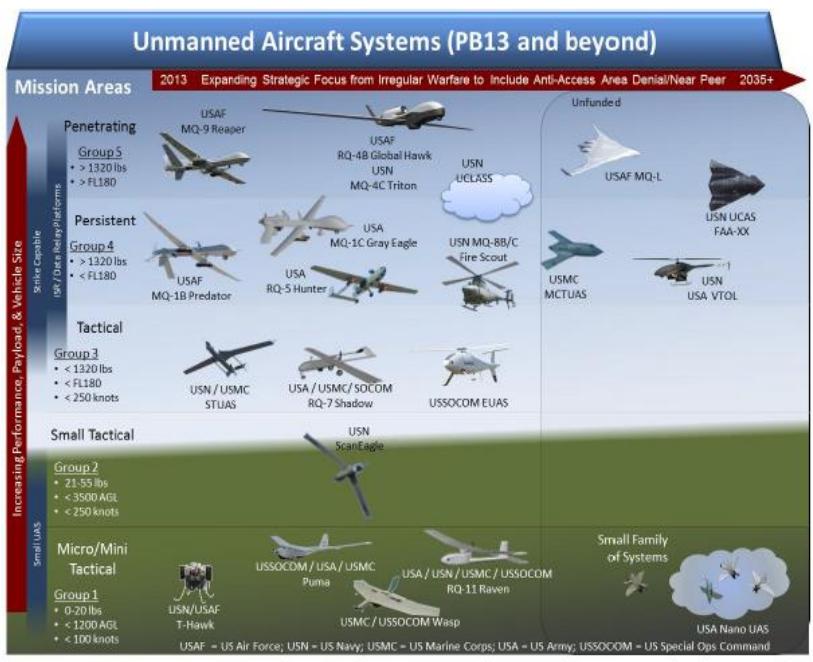

Figure 1 - DoD UAS Classification [3]

\subsection{ASTM UAS Classification}

ASTM (originally the American Society for Testing Materials) International [6] is an organization of producers, consumers and others interested in developing standards related to material safety. ASTM committee F38.02 has defined a "Terminology for UAS systems." However, this specification has been marked "Withdrawn 2014" and so is no longer recommended. This document defined 2 classes of UASs [7]:

- Light-UA: UASs with a gross takeoff weight of $1320 \mathrm{lb}$ or less.

- Mini-UA: UASs with a gross takeoff weight of $55 \mathrm{lb}$ or less. This class is further subdivided in 3 subclasses with maximum weights of $2 \mathrm{~kg}, 10 \mathrm{~kg}$, and $25 \mathrm{~kg}$.

Note that the weight limits of $1320 \mathrm{lb}$ and $55 \mathrm{lb}$ are similar to those used in DoD classification.

\subsection{EUROCAE UAS Classification}

European Organization for Civil Aviation Equipment (EUROCAE) is an organization of manufacturers, service providers, national and international aviation authorities and users from Europe and elsewhere [8]. EUROCAE is similar to RTCA in the United States. EUROCAE has two working groups related to UAS. WG-73 is titled "Unmanned Aircraft Systems (UAS)" while WG-93 is titled "Light Remotely Piloted Aircraft Systems (RPAS)." WG-73 deals with vehicles less than $25 \mathrm{~kg}$. These are further subdivided into 4 subclasses as follows:

- Harmless: less than $250 \mathrm{~g}$

- A0: Less than $1 \mathrm{~kg}$

- A1: Less than $4 \mathrm{~kg}$

- A2: Less than $25 \mathrm{~kg}$

The Harmless category is subject to light or very light market regulation while categories $\mathrm{A} 0-\mathrm{A} 2$ are subject to identification requirements and VLOS (Visual Line of Sight) limitations.

Note that many countries follow this classification in their guidelines. For example, United States does not require registration of UASs less than $250 \mathrm{~g}$ and requires it for all UASs between $250 \mathrm{~g}$ and $25 \mathrm{~kg}$. Irish Aviation authority requires registration of over $1 \mathrm{~kg}$ and pilot license for UASs over $4 \mathrm{~kg}$.

\subsection{RTCA UAS Categories}

Radio Technical Commission for Aeronautics (RTCA) is a US volunteer organization that develops technical guidance for use by government regulatory authorities and by industry [9]. Special Committee 228 is working on UAS standards. It has defined the following 4 UAS categories [10]:

- Category A: This applies to privately owned remote-controlled model aircrafts generally used by hobbyist for recreational or sport purposes. Their operation is restricted to visual line of sight (VLOS) and operational areas and altitudes are 
confined to pre-approved areas that do not mix with manned aircraft and are not flown within or in close proximity to densely populated areas.

- Category B: This includes UASs that will be operated within visual line of sight for non-recreational (commercial) purposes. Many of these will be operated in close proximity to people and may share airspace with a very limited subset of manned aircrafts (e.g., low flying rotorcrafts). These UAS operators will need to demonstrate knowledge and skills in their intended operations.

- Category C: These are similar to Category $\mathrm{B}$ but are operated beyond visual line of sight (BVLOS). The pilot would be licensed and must comply with the requirements of 14 CFR Part 91 [11]. This class would not operate in civil-use airports.

- Category D: These UASs will be allowed to use civil-use airports and would be required to follow $14 \mathrm{CFR}$. They will be allowed to "file and fly" similar to manned aircrafts in controlled air spaces.

Notice that these categories are based on operation and do not include any specific weight and height limitations.

\subsection{Proposed UAS Classification}

Of the 4 classifications discussed above, we like RTCA's classification. However, in addition to functionality, it is important to add weight limits so that the applicable regulations and operational limitations can be easily determined. Based on this our proposed UAS classification is as follows:

- Category A: Recreational UASs with weight less than $55 \mathrm{lb}$. These are privately owned and used for recreation or sport. These are unregulated but strictly limited in their operational areas. In the United States, this includes all UASs that currently require registration with the FAA.

- Category B: These are commercial UASs with a weight less than $55 \mathrm{lb}$ and operated within visual line of sight. These are regulated, but do not fly at or near airports.

- Category C: Commercial UASs with weight in the range of 55-1320 lb. These are allowed to fly beyond VLOS. They have more kinetic energy than the Category B UASs since they are heavier. This will affect their detect and avoid (DAA) time requirements.

- Category D: Commercial UASs with weight more than $1320 \mathrm{lb}$. These share airspace and airports with manned aircrafts. These are heavily regulated.

\section{UAS CNS Candidate Mission List}

As in the case of UAS classification, we also studied mission classification by the various standards and regulatory organizations. In this section, we briefly review these classifications and then propose a classification.

\subsection{EUROCAE Mission Classification}

EUROCAE specifies 3 categories of operations as shown in Figure 2 [12]:

- Open: This low-risk category allows operation without the involvement of aviation authorities. It is restricted to visual line of sight and away from crowds. Maximum altitude is also limited.

- Specific: This medium-risk category includes operations that need to be approved by national aviation authorities and require operator certification.

- Certified: This high-risk category has a regulatory regime similar to manned aviation.

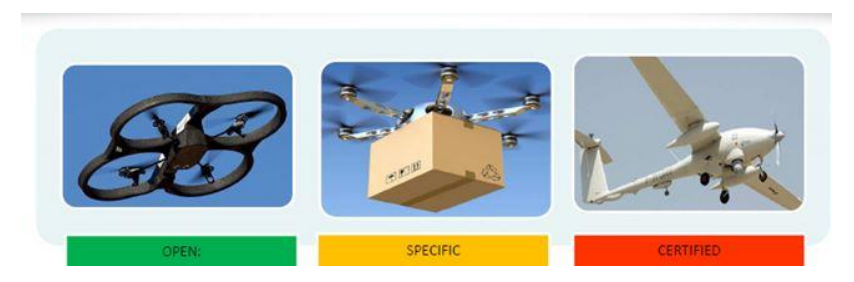

Figure 2 - EUROCAE Mission Classification [12] 


\subsection{ITU UAS Mission Classification}

International Telecommunication Union (ITU) recommendation M.2171 [13] includes a discussion on UAS missions. They recommend classifying missions as commercial or governmental. Both types of missions are classified by various applications and eight applications are briefly discussed in the recommendation. These are:

\section{Commercial:}

1. Electronic News gathering: Movie making

2. Transport: Cargo planes with reduced manpower

3. Monitoring: Inspections of oil fields, pipelines, rail lines, etc.

4. Communications infrastructure: Airborne relays for cell phones

5. Agriculture Services: Crop Dusting

\section{Governmental:}

6. Scientific Applications: Mapping, Surveying, animal monitoring, volcano monitoring

7. Security and Public Interest: Coast line inspection, Border surveillance, etc.

8. Humanitarian and Distress Support: Famine relief, search and rescue, etc.

The problem with this method of mission classification is that the number of applications is unlimited. New applications are evolving continuously. Wikipedia lists over 50 applications. UXV University website [14] lists over 300 applications.

\subsection{Levels of Autonomy}

Mission classification is also related to levels of autonomy. For example, beyond visual line of sight operation requires that the decisions be taken for any unforeseen situations. This will affect the level of communications.

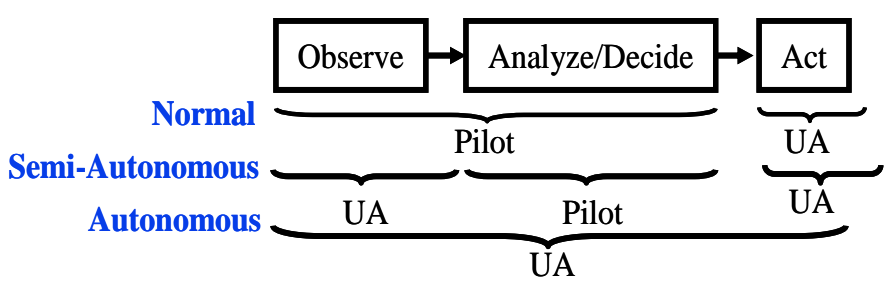

Figure 3 - Levels of Autonomy

All operations have 3 components: Observation, Analysis/Decision, and Action. As shown in Figure 3 , depending upon the division of responsibility between the UAS and the pilot, there are three levels of autonomy:

Normal Autonomy: This is the level at which low-cost recreational UASs are already operating currently. The pilot observes the UAS at all time, analyzes the situation and sends control actions that are executed by the UA. Currently, small UASs are able to carry out the following actions with minimal pilot intervention:

- Reach a specified altitude

- Hover

- Take-off and Landing

- Return to Home

- Follow me

- GPS waypoint navigation

These are considered within minimal/normal level of autonomy.

Semi-Autonomous: In this case, the UAS observes the situation, for example, another UAS or object (bird) in the vicinity, sends the observation to the pilot. The pilot makes a decision and sends instructions to the UA. This has significant communication overhead in both directions.

Autonomous: In this case, the UAS is able to observe, make decisions based on a set of rules (or machine learning) and takes appropriate actions. This is similar to self-driving cars. In this case, the communication overhead is lower than that in semiautonomous case.

\subsection{Proposed Mission Classification:}

Rather than list applications as mission types, we believe classifying missions by their general 
characteristics that determine the communication requirements will be more useful. Based on this realization we propose to extend the UAS classification proposed earlier to mission classification. We propose four categories with the fourth category having further subcategories as follows:

- Category A: These are recreational missions that are limited to VLOS and below $200 \mathrm{ft}$ AGL. Their velocity is low and so the risk is minimal. The UASs have normal/minimal levels of autonomy.

- Category B: These are commercial missions that are also limited to VLOS. To keep them away from recreational missions, there is a proposal to allow them to fly between 200 and $400 \mathrm{ft}$ AGL. They are also low velocity and require minimal operator training. The UASs have nomal/minimal levels of autonomy.

- Category C: These are commercial missions that are beyond VLOS and may use larger Category C (up to $1320 \mathrm{lb}$ ) aircrafts. They share the airspace with Category B and do not share controlled airspace or airports. Because of the larger distances involved and no visual line of sight, the UASs are either semiautonomous or autonomous.

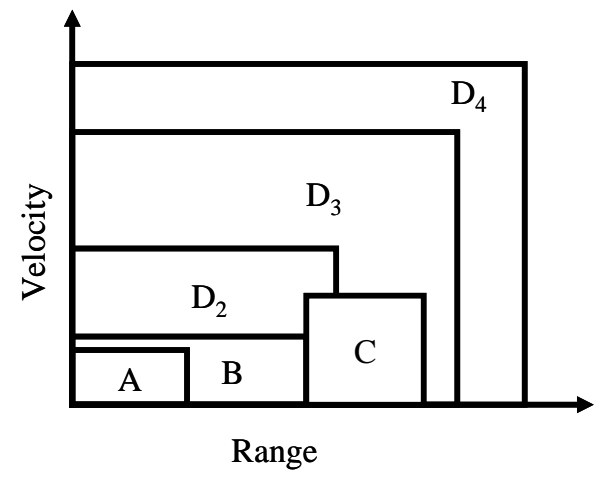

Figure 4- Proposed Mission Categories

- Category D: These are commercial missions similar to manned aircrafts. They need to assess to the controlled airspaces. Again, because of the large distances involved, the UASs used in this mission category are either semi-autonomous or autonomous. Their communications requirements depend upon the phases of flights. Therefore, this category is further subdivided into 4 sub-category as follows:

- Subcategory D1: On-Ground at the airport.

- Subcategory D2: Taxi and takeoff. Higher velocity requires special datalink designs.

○ Subcategory D3: En-route. High velocity and long distances require very strict communication requirements.

- Subcategory D4: Oceanic. Since most ground based systems will not be reachable. Only satellite and aircraft-to-aircraft peer communications are possible.

Figure 4 depicts these mission categories using their range and velocity as discriminators. Note that range is implicitly related to weight since longer ranges will require more fuel and higher weight.

\section{UAS Mission Class Demand Forecast}

Early UAS demand forecasts are available from the ITU and RTCA, with more recent figures given by the FAA. One problem with any forecast is that the applications are just starting to emerge, but are not feasible due to regulations not being ready. Once the regulations are set (as is now the case for FAA Part 107 [15]) the demands are going to skyrocket, particularly in the commercial small UAS area.

Table 1 - UAS Forecast [16]

\begin{tabular}{|l|r|}
\hline Altitude & \# of UAs \\
\hline Below $3000 \mathrm{ft}$ & 24,038 \\
\hline Between $3000 \mathrm{ft}$ and $12,000 \mathrm{ft}$ & 29,631 \\
\hline Between $12,000 \mathrm{ft}$ and $30,000 \mathrm{ft}$ & 988 \\
\hline Above $30,000 \mathrm{ft}$ & 2,560 \\
\hline
\end{tabular}

Table 1 gives the UAS demand forecasts set forth in RTCA DO-320 [16]. RTCA notes that these numbers do not include public aircrafts that will not be using ITU-R allocated UAS Safety spectrum. Also, $50 \%$ of these are small UASs operating beyond VLOS.

Both ITU and RTCA forecasts are now dated and are no longer applicable. These forecasts are based on extending the current manned aircraft demand to unmanned aircrafts. However, this is 
questionable since the applications for unmanned aircrafts are very different from manned aircrafts. Price points for manned and unmanned aircrafts are also very different. Most of these applications currently do not use aircrafts at all. For example, agriculture is mostly done by tractors. The number of unmanned aircrafts required for agriculture should be related to the number of tractors currently in use. In general, unmanned aircrafts are more similar to selfdriving cars than manned aircrafts. The FAA's forecast [17] is the latest and is included in Table 2.

Table 2 - FAA Demand Forecast for Small UAS (in Million Units) [17]

\begin{tabular}{|l|l|l|l|l|l|}
\hline & $\mathbf{2 0 1 6}$ & $\mathbf{2 0 1 7}$ & $\mathbf{2 0 1 8}$ & $\mathbf{2 0 1 9}$ & $\mathbf{2 0 2 0}$ \\
\hline Recreational & 1.9 & 2.3 & 2.9 & 3.5 & 4.3 \\
\hline Commercial & 0.6 & 2.5 & 2.6 & 2.6 & 2.7 \\
\hline Total & 2.5 & 4.8 & 5.5 & 6.1 & 7.0 \\
\hline
\end{tabular}

FAA [17] and NASA [1] documents indicate that the numbers of small UAS requiring registration in the US had reached 469,950 registered users by May 122016 with most of these being model aircraft and hobbyists. The FAA included a sales forecast anticipating 4.3 million hobbyist (model aircraft) and 2.7 million commercial (non-model aircraft) by the year 2020. The Teal Group further produced a forecast for the numbers of commercial sUAS predicting 52,000 higher-end sUAS (average sale price $\$ 40 \mathrm{~K}$ ) and 490,500 lower-end sUAS (average sale price $\$ 2.5 \mathrm{~K}$ ) for a total of 542,500 registered commercial sUAS by 2020 . Whether the higher FAA numbers or lower Teal Group numbers are used, it is clear that the UTM system must be able to support large numbers of units in the US with numbers potentially multiplied as regulations are amended to permit new commercial use cases.

Similar studies have been carried out worldwide. In Europe, SESAR has recently published a report [18] with relevant figures related to the expected drone market growth for the upcoming years. The report predicts a European demand of a value in excess of EUR 10 billion annually, by 2035, and over EUR 15 billion annually by 2050 . Civil missions are expected to generate the majority of that value (more than EUR 5 billion annually by 2035). The report highlights other sectors (defense and leisure) as the main sources of value in the near-term. Around 7 million consumer leisure drones are expected to be operating across Europe and a fleet of 400000 is expected to be used for commercial and government missions in 2050. According to the study by SESAR it is expected a demand in both rural and urban settings and will be reliant on beyond line of sight capabilities to be permitted. Some examples of missions in terms of the potential number of drones are shown in Table 3.

Table 3 - SESAR Forecast by Sector [18]

\begin{tabular}{|l|r|}
\hline Sector & Forecast \\
\hline Agriculture & 100,000 \\
\hline Energy & 10,000 \\
\hline Delivery & 100,000 \\
\hline Public safety and security & 50,000 \\
\hline
\end{tabular}

In addition to the total UAS worldwide market expectation, it is useful to consider the number of UAS that can safely operate within a given airspace. From a communications standpoint and using a typical airport as an example, SEATAC airport in Seattle, WA covers 3 square miles the majority of which includes airfield and runway space with a much smaller portion occupied by the airport terminal. Over-estimating the airport terminal space as 1 square mile would then give a conservative estimate for capacity planning purposes. The 2015 airport activity highlights for SEATAC lists total air passengers for the year as $42,340,537$, with passenger levels increased 12.9 percent from 2014 ranking SEATAC as the 13th busiest in U.S. [19]. This means that even SEATAC (a moderately-congested airport) on average accommodates $\mathrm{O}\left(10^{5}\right)$ passengers on a daily basis. Assuming that the vast majority of passengers are processed within a $10 \mathrm{hr}$ window, we can then say that SEATAC services $\mathrm{O}\left(10^{4}\right)$ passengers per hour. Assuming conservatively that only $10 \%$ percent of those passengers use $4 \mathrm{G}$ cellular and airport WiFi wireless services while in the terminal waiting to board flights, we estimate that ordinary Internet-profile wireless communications services can accommodate $\mathrm{O}\left(10^{3}\right)$ of communicating terminals per square mile. (Given the over-estimation of the airport terminal size, this number may be too conservative by multiple orders of magnitude.)

ADS-B capacity requirements are defined in RTCA DO-242A [20]. It is specified that ADS-B network must be designed to accommodate expected future peak airborne traffic levels, as well as any airport surface units within range. Estimations were made assuming an air traffic increase of a few 
percent each year until 2020. Figure 5 shows the expected scenario used to estimate ADS-B capacity:

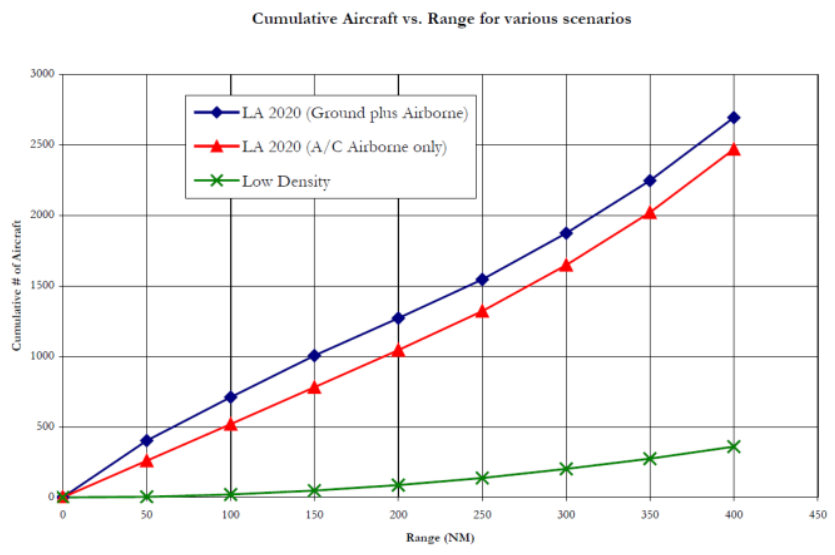

Figure 5 - Peak Traffic Based on Los Angeles Basin 2020 Scenario and Assumed Surface Traffic [20]

According to [20] ADS-B shall be capable of dealing with air traffic densities detailed in Table 4.

Table 4 - Number of UASs and Range Distribution [20]

\begin{tabular}{|r|r|r|r|r|}
\hline $\begin{array}{c}\text { Range } \\
\text { (NM) }\end{array}$ & \multicolumn{3}{|c|}{ LA Basin 2020 } & $\begin{array}{c}\text { Low } \\
\text { Density }\end{array}$ \\
\hline & $\begin{array}{c}\text { On- } \\
\text { the- } \\
\text { Ground }\end{array}$ & $\begin{array}{c}\text { Airborne } \\
\text { Only }\end{array}$ & $\begin{array}{c}\text { Total } \\
\text { Units }\end{array}$ & $\begin{array}{c}\text { Total } \\
\text { Units }\end{array}$ \\
\hline 50 & 143 & 260 & 403 & 4 \\
\hline 100 & 190 & 520 & 710 & 20 \\
\hline 150 & 225 & 781 & 1,006 & 48 \\
\hline 200 & 225 & 1,045 & 1,270 & 88 \\
\hline 250 & 225 & 1,321 & 1,546 & 138 \\
\hline 300 & 225 & 1,648 & 1,873 & 203 \\
\hline 350 & 225 & 2,021 & 2,246 & 274 \\
\hline
\end{tabular}

\begin{tabular}{|l|r|r|r|r|}
\hline 400 & 225 & 2,469 & 2,694 & 360 \\
\hline
\end{tabular}

According to figures in Table 4, the density of airborne aircraft is taken to be constant in range from the center of the area out to 225 nautical miles (5.25 aircraft/NM), i.e., the inner circle of radius $1 \mathrm{NM}$ would contain approximately five aircraft, as would the ring from 224 to $225 \mathrm{NM}$. The density will also be constant in area from $225 \mathrm{NM}$ to $400 \mathrm{NM}$ (0.00375 aircraft/NM2).

These figures did not estimate the UAS upcoming paradigm. Depending on the scenario contemplated, the UAS traffic density could be considerably higher. Even without taking into account the future scenario, surveillance systems based on the data transmission on $1090 \mathrm{MHz}$ is already facing some saturation issues, some of which has been made public by the media $[21,22,23]$.

Even if the saturation issue could be minimized by using alternative carrier frequencies, ADS-B standards present some well-known security issues [24]. Some of the identified vulnerabilities are shown in Tables 5-7.

Accordingly, to ICAO recommendations, future development of ADS-B technology should address security issues. Studies should be made to identify potential encryption and authentication techniques, taking into consideration the operational need of air to ground and air to air surveillance applications.

For all the reasons presented above, ADS-B will not be considered as a valid enough surveillance system to enable the integration of UAS missions within controlled and uncontrolled airspaces and therefore alternative systems will be developed.

Table 5 - ADS-B Confidentiality Issues [24]

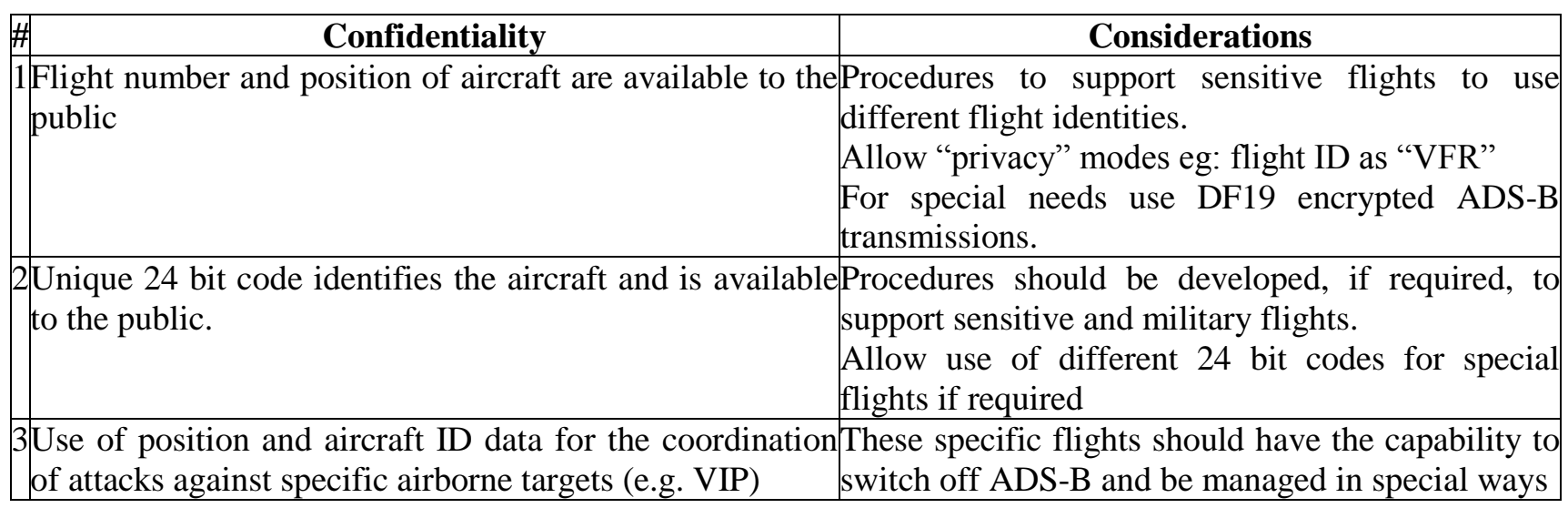




\begin{tabular}{|l|l|l|}
$4 \begin{array}{l}\text { Use of position and aircraft ID data for economic } \\
\text { intelligence: surveillance of business aircraft or } \\
\text { commercial aircraft }\end{array}$ & $\begin{array}{l}\text { Legislative controls on retransmission could be } \\
\text { considered but likely to be ineffective }\end{array}$ \\
\hline 5 Re-transmission via Internet &
\end{tabular}

Table 5- ADS-B Integrity Issues [24]

\begin{tabular}{|c|c|}
\hline Integrity & Considerations \\
\hline $\begin{array}{l}1 \text { False messages: transmission of false message } \\
\text { from virtual aircraft (spoofing); risk of false alarm } \\
\text { (STCA), false traffic information, spuriou } \\
\text { separation manoeuvres. }\end{array}$ & $\begin{array}{l}\text { SATC operates not just using surveillance but correlate the } \\
\text { ssurveillance picture with voice communication, the flight } \\
\text { splan, controller expectations of "normal behaviour } \\
\text { If related risks warrant it (especially in high density } \\
\text { environments) additional functions can be provided to } \\
\text { warn and protect ATC. } \\
\text { ATC system protections can include : } \\
\text { schemes to match surveillance tracks with current flight } \\
\text { plan data state including position, route, level, identity etc } \\
\text { Alerting if the ADS-B track is outside route and vertical } \\
\text { clearance limits } \\
\text { Ability to decouple misleading data from a flight plan } \\
\text { Detection of positional data "jumps" (reasonableness } \\
\text { checking) } \\
\text { Warnings of potentially misleading data } \\
\text { Duplicate matches to a flight plan } \\
\text { Duplicate } 24 \text { bit codes } \\
\text { Duplicate FlightID on different targets } \\
\text { Not coupling ADS-B track data to a flight plan if the track } \\
\text { arrives into coverage at an unexpected position or arrives } \\
\text { into coverage at an unexpected time, or without co- } \\
\text { ordination } \\
\text { Ground station considerations could include the following } \\
\text { at additional cost } \\
\text { Use of direction finding capabilities to validate the } \\
\text { "quadrant" from which the data is receivedUse of active } \\
\text { SSR ranging to validate the range of the aircraft } \\
\text { Use of SSR, primary radar or multilateration } \\
\text { Automated tools to warn controllers of this potential } \\
\text { hazard. }\end{array}$ \\
\hline $\begin{array}{l}2 \text { Alteration of messages during their transmissi } \\
\text { between the ground stations and the ATM system }\end{array}$ & $\begin{array}{l}\text { Appropriate protections are required for the security of } \\
\text { ADS-B transmission network between Ground station and } \\
\text { ATC centre }\end{array}$ \\
\hline $\begin{array}{l}\text { Deleted messages: possible loss of airc } \\
\text { visualisation on controller display }\end{array}$ & $\begin{array}{l}\text { Appropriate protections are required for the security of } \\
\text { ADS-B transmission network between Ground station and } \\
\text { ATC centre. } \\
\text { Effect is somewhat identical to avionics failure. } \\
\text { Procedures are in place to manage this event. }\end{array}$ \\
\hline
\end{tabular}


Table 6 - ADS-B Availability Issues [24]

\begin{tabular}{|l|l|l|}
\hline \multicolumn{1}{|c|}{ Availability } & \multicolumn{1}{|c|}{ Considerations } \\
\hline $\begin{array}{l}\text { 1Jamming of a receiving ground station by } \\
\text { transmission of a high power signal on } 1090 \mathrm{MHz}\end{array}$ & $\begin{array}{l}\text { Effect is somewhat identical to ground station failure. } \\
\text { Procedures are in place to manage this event. } \\
\text { denies the positional data }\end{array}$ & $\begin{array}{l}\text { Effect is somewhat identical to ground station failure. } \\
\text { Procedures are in place to manage this event. } \\
\text { Avionics are becoming available that meld GPS with } \\
\text { inertial positional data to coast through. }\end{array}$ \\
\hline $\begin{array}{l}\text { 3 Transmission of a large amount of false messages } \\
\text { in order to saturate the channel of ground system } \\
\text { data processing, or the ATCO surveillance display } \\
\text { (spoofing) }\end{array}$ & $\begin{array}{l}\text { Effect is somewhat identical to ground station failure. } \\
\text { Procedures are in place to manage this event. } \\
\text { Ability to disconnect an ADS-B ground station (eg if data } \\
\text { flooding occurs) so to limit loss to a single sensor } \\
\text { Filtering ground station data based on range, on SIC/SAC, } \\
\text { on 24 bit codes }\end{array}$ \\
\hline
\end{tabular}

\section{Summary}

In this paper, we have discussed the key considerations that are required to set CNS requirements for the operation of Unmanned Air Systems (UAS) in the National Air Space (NAS). It observes the new FAA Part 107 regulations for operation of sUAS under $55 \mathrm{lb}$ [15], and it considers the NASA UTM concept of operations as the guideline for UAS air traffic management. The document provides a UAS CNS candidate mission list and discusses CNS needs within this mission context. The document next examines a demand forecast for the expected number of UAS sales as well as the numbers of UAS that could be operating in the same air space. A companion paper presents UAS CNS requirements based on these considerations [2].

\section{References}

[1] Kopardekar, Parimal, Joseph Rios, Thomas Prevot, Marcus Johson, Jaewoo Jung, and John E. Robinson III, 2016, Unmanned Aircraft System Traffic Management (UTM) Concept of Operations, 16th AIAA Aviation Technology, Integration, and Operations Conference Washington, D.C.

[2] Templin, Fred L., Greg Sheffield, Pedro TabosoBallesteros, Raj Jain, Denise Ponchak, 2017, Requirements for an Integrated UAS CNS
Architecture, 2017 Integrated Communications Navigation and Surveillance (ICNS) Conference, Washington D. C., 11 pp.

[3] Global Security, 2013, Unmanned Systems Integrated Roadmap, FY2013-2038, 168 pp., http://www.globalsecurity.org/intell/library/policy/do d/dod-uas-roadmap-2011-2036.pdf

[4] Wikipedia, 2017, Nautical Mile, https://en. wikipedia.org/wiki/Nautical_mile

[5] Wikipedia, 2017, Flight Level, https://en. wikipedia.org/wiki/Flight level

[6] Wikipedia, 2017, ASTM International, https:// en.wikipedia.org/wiki/ASTM International

[7] ASTM, 2007, Standard Terminology for Unmanned Air Vehicle Systems (Withdrawn 2014), ASTM F2395-07, 2 pp.

[8] Wikipedia, 2017, European Organization for Civil Aviation Equipment, https://en.wikipedia.org/wiki /European Organisation for Civil Aviation Equip $\underline{\text { ment }}$

[9] Wikipedia, 2017, Radio Technical Commission for Aeronautics, https://en.wikipedia.org/wiki /Radio_Technical_Commission_for_Aeronautics

[10] RTCA, 2007, UAS Guidance Material and Considerations for Unmanned Aircraft Systems, DO304, 314 pp. 
[11] US GPO, 2016, Electronic Code of Federal Regulations, Title 14: Aeronautics and Space Part 91 - General Operating and Flight Rules, http://www .ecfr.gov/cgi-bin/text-idx?node=14:2.0.1.3.10

[12] Rong, S., 2016, EASA need for Standards and AMC for Unmanned Aircraft, EUROCAE UAS Workshop, 18 pp., http://rpas-regulations.com /phocadownloadpap/02_14_EUROCAE/3_EUROCA E-UAS-Workshop_160304_EASA.pdf

[13] ITU-R, 2009, Characteristics of Unmanned Aircraft Systems and Spectrum Requirements to Support Their Safe Operation in Non-Segregated Airspace, 83 pp., https://www.itu.int/dms_pub/itur/opb/rep/R-REP-M.2171-2009-PDF-E.pdf

[14] UXV University, https://www.uxvuniversity .com/careers/

[15] Federal Aviation Administration (FAA), 2016, Summary of Small Unmanned Aircraft Rule (Part 107), Washington, DC, https://www.faa.gov luas/media/Part_107_Summary.pdf

[16] RTCA, 2010, Operational Services and Environmental Definition (OSED) for Unmanned Aircraft Systems (UAS), DO-320, 236 pp.

[17] FAA, 2016, FAA Aerospace Forecast, FY 20162036, https://www.faa.gov/data research/aviation /aerospace_forecasts/media/FY2016-

36_FAA_Aerospace_Forecast.pdf

[18] SESAR, 2016, European Drone Outlook Study SESAR Joint Undertaking, 93 pp. http://www .sesarju.eu/sites/default/files/documents/reports/Euro pean Drones Outlook Study 2016.pdf

[19] Port of Seattle, 2015, 2015 Airport Statistics (2015 Airport Activity Highlights), https://www. portseattle.org/About/Publications/Statistics/AirportStatistics/Pages/default.aspx

[20] RTCA, 2002, Minimum Aviation system Performance Standards for Automatic Dependent Surveillance Broadcast (ADS-B), DO-242A, 475 pp.

[21] Daily Mail, 2013, For nine minutes the screens were blank: Scare at Delhi airport after air traffic control blackout hits radar operations, http://www.dailymail.co.uk/indiahome/indianews/arti cle-2275825/For-minutes-screens-blank-Scare-Delhiairport-radar-blackout-hits-air-operations.html

[22] EJInsight, 2016, No worries, says CAD after flight falls off radar for 12 seconds, http://www.ejinsight.com/20161121-no-worries-sayscad-after-flight-falls-off-radar-for-12-seconds/

[23] Express, 2014, Dozens of aircraft vanish from air-traffic control radars sparking hacking fears, http://www.express.co.uk/news/world/482295/Dozen s-aircraft-VANISH-air-traffic-control-radars-ofEurope-skies

[24] ICAO, 2008, Guidance Material: Security Issues Associated with ADS-B, 6 pp.

\section{Acknowledgements}

This work was conducted under NASA contract NNA16BD84C titled: ""Revolutionary, Advanced universal, reliable, always available, cyber secure and affordable Communication, Navigation, Surveillance (CNS) Options for all altitudes of UAS operations."

\section{Email Addresses}

Fred L. Templin (fred.l.templin@ boeing.com)

Raj Jain (jain@acm.org)

Greg Sheffield (greg.l.sheffield@boeing.com)

Pedro Taboso-Ballesteros

(pedro.tabosoballesteros@boeing.com)

Denise Ponchak (denise.s.ponchak@nasa.gov)

\section{Conference Identification}

2017 Integrated Communications Navigation and Surveillance (ICNS) Conference

April 18-20, 2017 